\title{
La filature cotonnière qui a tissé une communauté Joël Therrien
}

Mon travail examine mon héritage franco-ontarien ainsi que la population francophone de Welland autour de la fabrique de coton Empire. Ma recherche porte essentiellement sur l'émergence et le déclin relativement récent des communautés francophones du sud de l'Ontario. Ce phénomène est rendu par l'entropie inhérente à mes créations interactives, lesquelles invitent également les spectateurs à briser le décorum des galeries d'art et à éveiller en eux le sens ludique. Par exemple, La filature cotonnière qui a tissé une communauté permet aux spectateurs de s'engager physiquement dans le fonctionnement d'une animation lumineuse reproduisant le geste de la main qui file le coton, à travers différents schémas de machines employées dans la fabrique de coton pour produire une ceinture fléchée, vêtement francophone traditionnel. Le schéma des machines est imprimé sur des chutes de coton cousues ensemble pour former une boucle continue. Outre le fuseau de l'ancienne fabrique de coton servant de poignée pour activer le mécanisme, ce mouvement procure aux spectateurs une expérience tactile renforcée par le son machinal déclenché dès qu'il y a interaction. Mon objectif lors de la création de cette œuvre récente, consiste à produire des effets apparemment sophistiqués à partir de simples processus mécaniques.

La filature cotonnière qui a tissé une communauté : contre-plaqué, impressions à jet d'encre sur coton, fil de coton, rouleaux d'acier, ampoule rouge, boitier électrique, fil de terre, aluminium, fuseau de la fabrique de coton, clous, vis, teinte, vernis ; 69 1/2”x 28”x 28”, 2013.

(Traduction : Catherine Parayre) 


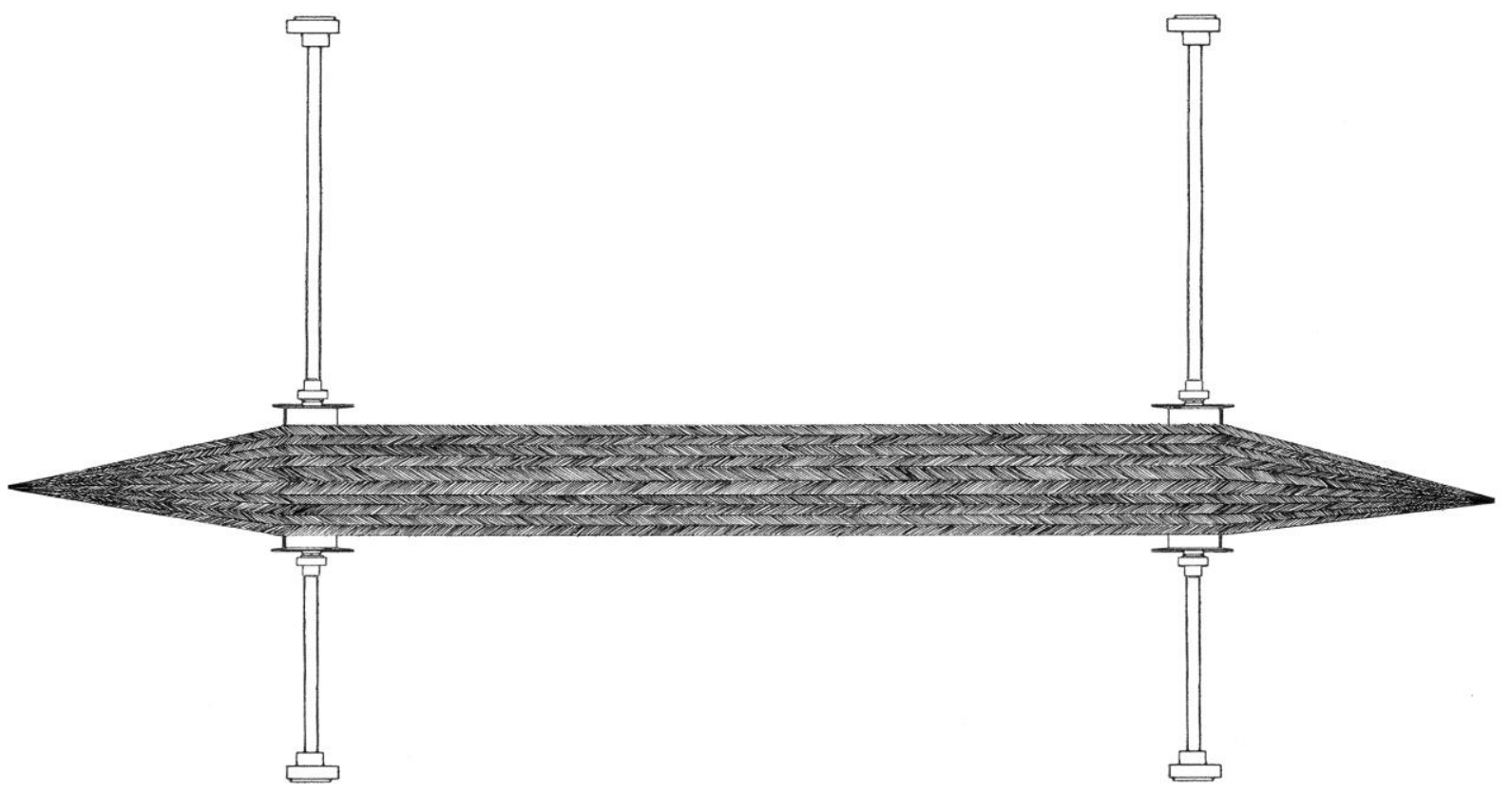



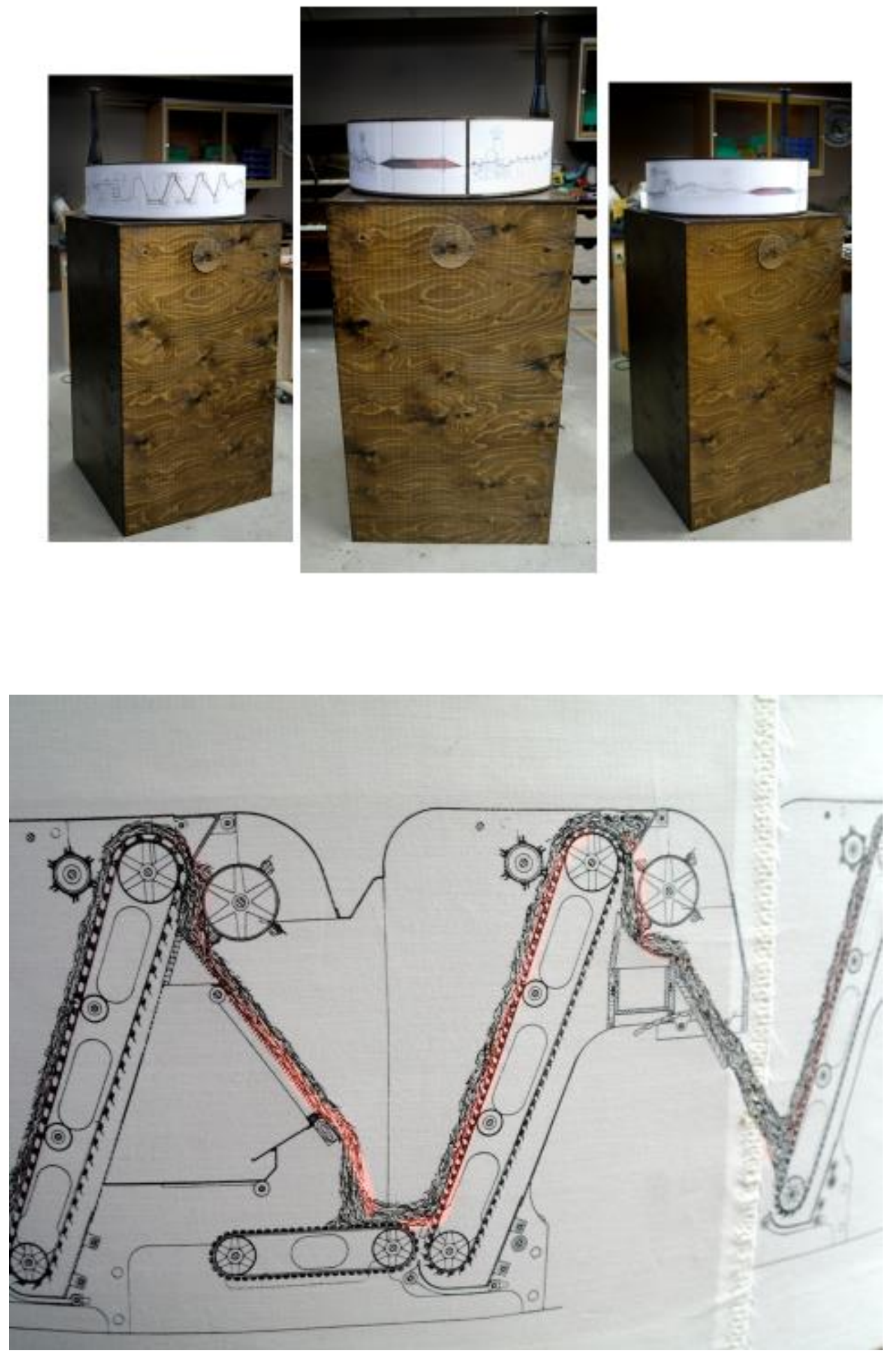

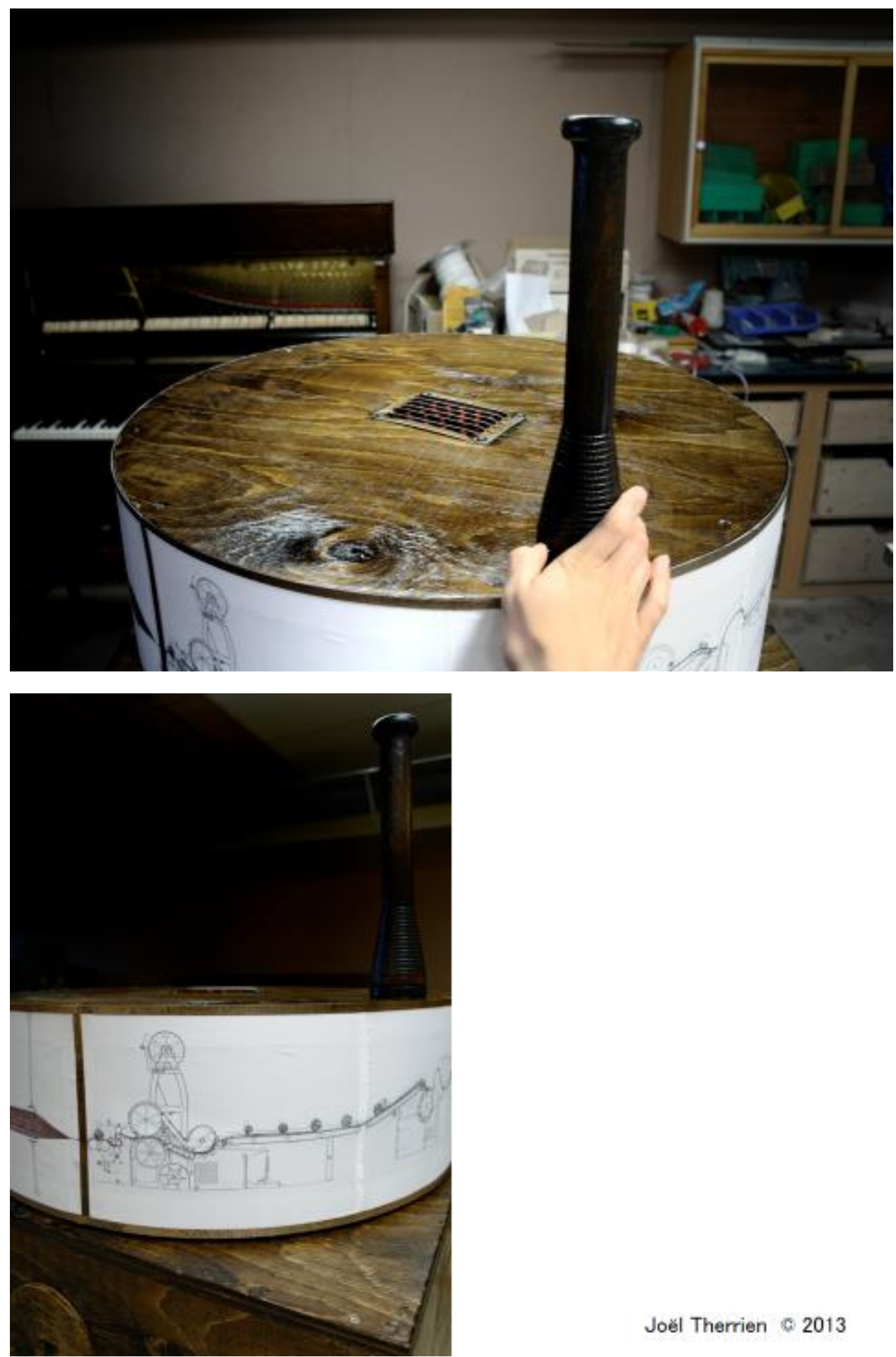